(2) Open Access Full Text Article

\title{
Hypertriglyceridemia, an important and independent risk factor for acute pancreatitis in patients with type 2 diabetes mellitus
}

This article was published in the following Dove Press journal:

Therapeutics and Clinical Risk Management

13 April 2017

Number of times this article has been viewed

\author{
Oana Albai' \\ Deiana Roman ${ }^{2}$ \\ Mirela Frandes ${ }^{2}$ \\ 'Second Department of Internal \\ Medicine, "Department of Functional \\ Sciences, "Victor Babes" University \\ of Medicine and Pharmacy, \\ Timisoara, Romania
}

Purpose: Acute pancreatitis (AP) is a frequent inflammatory disease of the pancreas with multiple causes, among which high triglyceride (TG) level is the most common. The main purpose of this study has been to research the prevalence of AP in patients with diabetes mellitus (DM) and to underline the importance of hypertriglyceridemia (HTG) as a risk factor in triggering AP. The possible link between AP and glycemic control has been studied also, alongside some cardiovascular risk factors and long-term diabetes complications.

Patients and methods: The patient cohort comprised 1,586 patients with DM, admitted to the Internal Medicine Clinic of Diabetes, Nutrition and Metabolic Disease within the Emergency Hospital in Timisoara between January and August 2016. Following a series of clinical and biological investigations, these patients were diagnosed with AP. The patients' antidiabetic treatment and chronic diabetes-related complications have also been recorded.

Results: The prevalence of pancreatitis in this group of patients was $3.7 \%$. The presence of pancreatitis was associated with a higher HbA1c ( $8.5 \%$ vs $7.7 \% ; P<0.001)$, fasting glycemia (167.5 vs $95 \mathrm{mg} / \mathrm{dL} ; P<0.001$ ), postprandial glycemia ( $244.5 \mathrm{vs} 118 \mathrm{mg} / \mathrm{dL} ; P<0.001$ ), total cholesterol (256.5 vs $189.5 \mathrm{mg} / \mathrm{dL} ; P<0.001)$, low-density lipoprotein cholesterol (LDLc) (208.7 vs $112.8 \mathrm{mg} / \mathrm{dL} ; P<0.001$ ), and TGs (495 vs $161 \mathrm{mg} / \mathrm{dL} ; P<0.001$ ). HDL cholesterol (HDLc) was found to be a significant protective factor against the risk of pancreatitis. On the contrary, high LDLc values were a significant risk factor for pancreatitis along with high non-HDLc and high TG values, respectively.

Conclusion: The development of AP events in patients with DM is associated with unsatisfactory glycemic control, HTG, hypertension, and the presence and severity of DM chronic complications. In this study, the prevalence of AP events in patients with DM was 3.7\%.

Keywords: diabetes mellitus, hypertriglyceridemia, acute pancreatitis, insulin resistance

\section{Introduction}

Acute pancreatitis (AP) is an inflammatory disease of the pancreas, being one of the most frequent and severe gastrointestinal conditions requiring hospital admission. In the USA, the annual cost of AP-related admissions is $\sim \$ 2.6$ billion. Worldwide, the incidence of AP ranges between 4.9 and 73.4 cases per 100,000 individuals annually. ${ }^{1}$

The incidence of AP increases with age in both women and men, $>60 \%$ of cases being recorded in adults. Also, the frequency of AP is two- to threefold higher in the Afro-American population, compared to the Caucasian population. ${ }^{2,3}$

AP has multiple causes, alcohol abuse and gallstone migration in the common bile duct being listed as the main two. Gallstones can consist of cholesterol or biliary matter that consolidates in solid masses which obstruct the pancreatic canals, leading
Second Department of Internal Medicine,

"Victor Babes" University of Medicine

and Pharmacy, 2 Eftimie Murgu, 30004I

Timisoara, Romania

Tel +40744544354

Fax +40 256462856

Email oana_olari@yahoo.com
Therapeutics and Clinical Risk Management 2017:13 515-522

$5 \mathbf{5}$ 
to the accumulation of pancreatic liquid and prompting the pancreatic inflammatory process. ${ }^{4}$

Alcohol abuse is the second cause of AP, having an increased frequency in the middle-aged population, peaking between the age of 45 and 55 years. Alcohol has toxic metabolic effects on pancreatic acini. The mechanisms that determine these effects are the obstruction of small ducts, precocious enzymatic activation, the altering of blood flow, altering of the mobility of Oddi's sphincter, and the stimulation of colecystokinin and secretin secretion. ${ }^{5}$

Increased triglyceride (TG) values represent another extremely important cause of AP, values over $1,000 \mathrm{mg} / \mathrm{dL}$ being accompanied by a very high risk of AP. Although the exact mechanism is unknown, it seems that the toxic effects are a consequence of TG being hydrolyzed in short-chain fatty acids. HTG can be inherited or, more frequently, it can be the effect of an inadequate diet. ${ }^{6}$

Other causes of AP are represented by medication, smoking, invasive exploratory procedures (ERCP), infections, hypercalcemia, trauma, and neoplastic processes. ${ }^{7-9}$ AP represents a potential life-threatening medical emergency requiring hospitalization, investigations, monitoring, and treatment. The most common onset involves acute abdominal pain, nausea, and severely altered general status. ${ }^{10}$

The final diagnosis is set based on laboratory tests (increased values of lipase and amylase), whereas for establishing the severity and the presence of complications, medical imaging techniques such as abdominal ultrasound, computed tomography, or magnetic resonance imaging are necessary. In AP, the endocrine function of the pancreas is affected, altering the carbohydrate metabolism. This is the reason for which high levels of glucose represent a disease severity factor, being included in the RANSON score of AP severity and mortality. ${ }^{11}$

Diabetes mellitus (DM) is a chronic, heterogeneous disease with a progressive evolution and multiple complications, its incidence being cited to have an important increase in the latest years. ${ }^{12}$ Besides the two main types of diabetes (type 1 and type 2), secondary types have been identified, among which one of the leading causes is represented by pancreatic diseases such as $\mathrm{AP}$, chronic pancreatitis (CP), cystic fibrosis, or pancreatic cancer. It has been proven that the risk of developing DM significantly increases 5 years after the first AP episode. ${ }^{13}$

Dyslipidemia is frequently encountered in diabetic patients, its diagnosis being mandatory both when the DM diagnosis is set and later through periodic evaluations. ${ }^{14,15}$

Insulin deficiency and/or insulin resistance, present in various degrees in the diabetic patient, contribute to quantitative and qualitative modifications in all lipoprotein
(LP) classes. The characteristics of dyslipidemia in diabetic patients are hypertriglyceridemia (HTG); increased lowdensity lipoprotein cholesterol (LDLc) levels; and decreased apo-B, high-density lipoprotein cholesterol (HDLc), and apo-A (its concentration is proportional to the degree of glycemic control). ${ }^{16}$

HTG represents the most common modification, the three mechanisms responsible being decreased LPL activity leading to a decreased conversion of very low density lipoprotein (VLDL) to LDL, the stimulation of the hormone-sensitive lipase that increases free fatty acid flow to the liver which, in turn, stimulates VLDL and apo-B100 production, and cholesterylester transfer protein (CETP) increased action leading to anomalies of VLDL particle composition. ${ }^{17}$

Postprandial hyperlypidemia, being of both exogenous and endogenous nature, has imbalance as a primary mechanism between excess dietary lipids, on one side, and the increased production of VLDL and chylomicrons, on the other. Increased hepatic production of VLDL that is TG rich and reduced VLDL clearance seem to be key components of the pathophysiology of this dyslipidemia. Small particles of LDLc come from VLDL precursors. Particularly, the reduction of HDLc particles is due to the reduction of bigger $\mathrm{HDL}_{2 \mathrm{~b}}$ subspecies, which have antiatherogenic role and to the relative or absolute increase of small, dense $\mathrm{HDL}_{3 \mathrm{~b}}$ and $\mathrm{HDL}_{3 \mathrm{c}}$ subspecies, which have reduced cholesterol take-up capacity. ${ }^{15,18}$

Although lifestyle optimization, which entails a healthy diet and physical exercises, can alleviate atherogenic dyslipidemia characteristic of type 2 diabetes patients, medication is necessary for attaining therapy goals.

\section{Aim of the study}

Having these premises, the main objectives of this study were to determine the prevalence of AP in diabetic patients and to underline the importance of HTG as a risk factor in triggering AP.

Also, the link between the occurrence of AP events and the following parameters was studied:

- the quality of glycemic control;

- cardiovascular risk factor components;

- the presence of DM's chronic complications.

\section{Patients and methods}

\section{Study design and patients}

In this retrospective cohort-based study, 1,586 patients with DM, 809 males (51\%) and 777 females (49\%) with a median age of 59 years, admitted to the Internal Medicine Clinic of Diabetes, Nutrition and Metabolic Diseases within 
the "Pius Brinzeu" Emergency Hospital of Timisoara were enrolled between January and August 2016. The study cohort included patients without a history of $\mathrm{AP}$ or $\mathrm{CP}$ and meeting the inclusion criteria. The study protocol was approved by the "Pius Brinzeu" Emergency Hospital Timisoara Ethics Committee. All the patients whose data were collected for this study's purpose provided written informed consent for the acquisition, analysis, and publishing of the anonymized data collected during their hospital admission.

The following parameters have been investigated: age, gender, type and duration of DM, weight $(\mathrm{kg})$, height $(\mathrm{cm})$, body mass index $\left(\mathrm{kg} / \mathrm{m}^{2}\right)$, abdominal circumference $(\mathrm{cm})$, data regarding alcohol consumption and smoking habits, presence of gallstones, and arterial hypertension (AHT). Also, lipidic parameters have been inquired: total cholesterol, TGs, HDLc, and LDLc. The presence of chronic complications related to DM was tested: microvascular diseases (diabetic retinopathy, chronic kidney disease), macrovascular diseases (stroke, ischemic heart disease, diabetic arteriopathy), and neuropathy. The quality of the glycemic control has been evaluated by using glycated hemoglobin (HbA1c), fasting glycemia (mg/ $\mathrm{dL})$, and postprandial glycemia $(\mathrm{mg} / \mathrm{dL})$.

The AP diagnostic was determined based on the typical clinical symptoms (typical upper abdominal pain, nausea, vomiting, and altered general status), clinical examination, laboratory tests (amylase and lipase), as well as medical imaging.

The antidiabetic treatment that the patients were undergoing was also recorded: dietary regimen, insulin, oral antidiabetics, antidiabetics, and insulin association (Figure 1).

\section{Statistical analysis}

Data were presented as mean \pm standard deviations for continuous variables with Gaussian distribution, median (interquartile range) for continuous variables without Gaussian distribution, or percentage (absolute frequency) for categorical variables. Continuous variable distributions were tested for normality using the Kolmogorov-Smirnov's test and for equality of variances by using Levene's test.

For assessing the significance of the differences between groups, the Student's $t$-test (means, Gaussian populations), Mann-Whitney $U$ test (medians, non-Gaussian populations), and Pearson chi-square or Fisher's exact test (proportions) were used. To evaluate the influence of one or more confounding factors in dichotomous outcomes, univariate and multivariate logistic regression models were derived; the goodness of fit was calculated using Nagelkerke's $R^{2}$ method. Linearity of the continuous variables with respect to the logit of the dependent variable was assessed through the Box-Tidwell procedure.

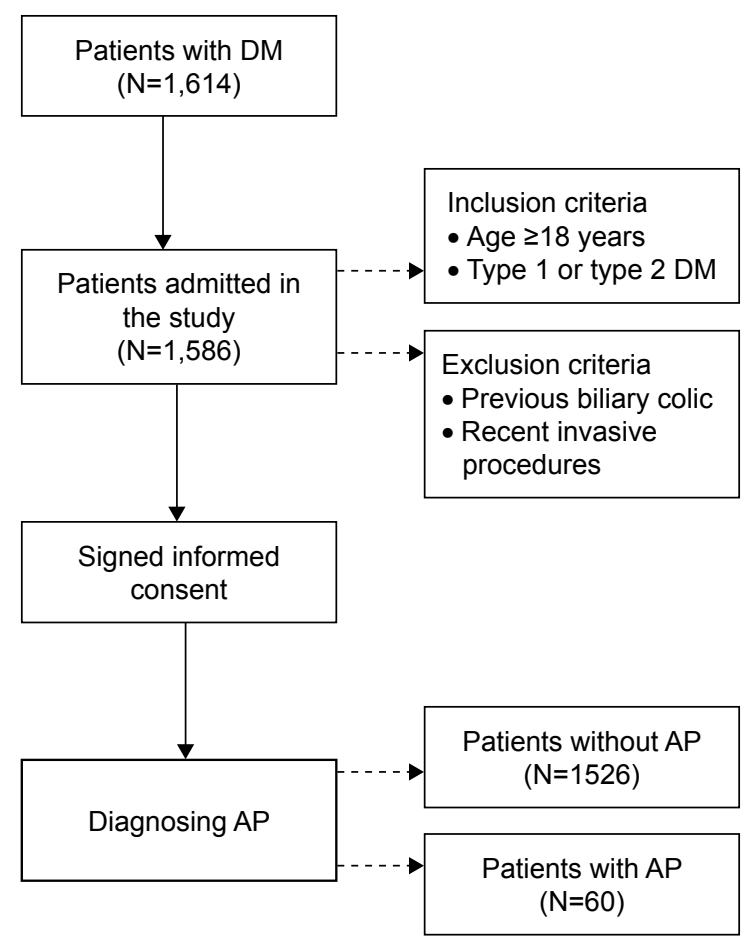

Figure I Diagram of the study flow.

Abbreviations: DM, diabetes mellitus; AP, acute pancreatitis.

Data were analyzed by using the SPSS v.17 software (SPSS Inc., Chicago, IL, USA) and the R software packages (v.3.3) for statistical computing. A $P$-value $<0.05$ was considered as the threshold for statistical significance, and a confidence level of 0.95 was considered for estimating intervals.

\section{Results}

The prevalence of pancreatitis in our group of patients was $3.7 \%$. The studied cohort had similar characteristics of the population of patients admitted to our Diabetes clinic; thus it can be concluded that the sample is representative for this population: $51 \%$ were males, $92.4 \%$ of them had type 2 diabetes mellitus, and they had a median body mass index of $30 \mathrm{~kg} / \mathrm{m}^{2}$. The prevalence of diabetes complications and comorbidities was similar to those found in the general diabetic population.

The detailed baseline characteristics of the studied sample are presented in Table 1 . The presence of pancreatitis was associated with a higher $\mathrm{HbA1c}(8.5 \%$ vs $7.7 \% ; P<0.001)$, fasting glycemia ( $167.5 \mathrm{vs} 95 \mathrm{mg} / \mathrm{dL} ; P<0.001$ ), postprandial glycemia (244.5 vs $118 \mathrm{mg} / \mathrm{dL} ; P<0.001)$, total cholesterol ( 256.5 vs $189.5 \mathrm{mg} / \mathrm{dL} ; P<0.001)$, LDLc (208.7 vs $112.8 \mathrm{mg} / \mathrm{dL}$; $P<0.001$ ), and TG (495 vs $161 \mathrm{mg} / \mathrm{dL} ; P<0.001)$.

At the same time, the presence of pancreatitis was associated with a higher prevalence of hypertension $(85 \%$ vs 
Table I Baseline characteristics of the patients

\begin{tabular}{|c|c|}
\hline Number of patients & I,586 \\
\hline Age $(\text { years })^{a}$ & $59(54-66)$ \\
\hline \multicolumn{2}{|l|}{ Gender $^{\mathrm{b}}$} \\
\hline Male & $51 \%(809)$ \\
\hline Pancreatitis $^{\mathrm{b}}$ & $3.7 \%(60)$ \\
\hline \multicolumn{2}{|l|}{ DM type ${ }^{b}$} \\
\hline Type I & $7.6 \%(124)$ \\
\hline Type 2 & $92.4 \%(1,465)$ \\
\hline $\mathrm{HbAlc}(\%)^{\mathrm{a}}$ & $7.8(6.9-9)$ \\
\hline Fasting glycemia $(\mathrm{mg} / \mathrm{dL})^{a}$ & $96(82-116)$ \\
\hline Postprandial glycemia $(\mathrm{mg} / \mathrm{dL})^{\mathrm{a}}$ & $120(96-164)$ \\
\hline BMI $\left(\mathrm{kg} / \mathrm{m}^{2}\right)^{\mathrm{a}}$ & $30(26.88-33.2)$ \\
\hline \multicolumn{2}{|l|}{$\mathrm{HBP}^{\mathrm{b}}$} \\
\hline Normal & $20.9 \%(332)$ \\
\hline Prehypertension & $5.2 \%(83)$ \\
\hline Hypertension stage I & $34.3 \%(544)$ \\
\hline Hypertension stage II & $39.5 \%(642)$ \\
\hline Alcohol ${ }^{b}$ & $27.7 \%(439)$ \\
\hline Smoking ${ }^{\mathrm{b}}$ & $33 \%(523)$ \\
\hline \multicolumn{2}{|l|}{ Gallstones ${ }^{\mathrm{b}}$} \\
\hline Absent or asymptomatic gallstones & $80 \%(1,269)$ \\
\hline Symptomatic gallstones (episodes of biliary colic) & $9 \%(142)$ \\
\hline Complicated cholelithiasis & II\% (I75) \\
\hline Total cholesterol $(\mathrm{mg} / \mathrm{dL})^{\mathrm{a}}$ & $191.5(157-228)$ \\
\hline $\mathrm{HDLc}(\mathrm{mg} / \mathrm{dL})^{\mathrm{a}}$ & $43(37-52)$ \\
\hline LDLc (mg/dL) ${ }^{\mathrm{a}}$ & II 4 (83-146.4) \\
\hline Non-HDLc (mg/dL) ${ }^{\mathrm{a}}$ & $146(1 \mid 3-182)$ \\
\hline Triglycerides $(\mathrm{mg} / \mathrm{dL})^{\mathrm{a}}$ & $164(112-245)$ \\
\hline \multicolumn{2}{|l|}{ Diabetic polyneuropathy ${ }^{\mathrm{b}}$} \\
\hline Absent & $62.9 \%(998)$ \\
\hline Signs without symptoms of neuropathy & $36.8 \%(584)$ \\
\hline $\begin{array}{l}\text { Symptomatic mild diabetic polyneuropathy } \\
\text { (sensory, motor, or autonomic symptoms) }\end{array}$ & $0.3 \%(4)$ \\
\hline \multicolumn{2}{|l|}{ Diabetic arteriopathy ${ }^{b}$} \\
\hline Absent & $90.4 \%(1,434)$ \\
\hline Asymptomatic & $4.5 \%(72)$ \\
\hline $\begin{array}{l}\text { Intermittent claudication after }>200 \mathrm{~m} \text { of pain } \\
\text { free walking }\end{array}$ & $3.8 \%(60)$ \\
\hline Intermittent claudication after $<200 \mathrm{~m}$ of walking & $0.5 \%(8)$ \\
\hline Rest pain & $0.3 \%(5)$ \\
\hline Ischemic ulcers or gangrene & $0.5 \%(7)$ \\
\hline \multicolumn{2}{|l|}{ Diabetic retinopathy ${ }^{b}$} \\
\hline Absent & $79.9 \%(1,268)$ \\
\hline Background retinopathy & $16.1 \%(255)$ \\
\hline Pre-proliferative diabetic retinopathy & $2.2 \%(35)$ \\
\hline Proliferative diabetic retinopathy & $1.8 \%(28)$ \\
\hline \multicolumn{2}{|l|}{ Treatment ${ }^{\mathrm{b}}$} \\
\hline DPP-4 inhibitors & $0.6 \%(10)$ \\
\hline Insulin & $36.9 \%(586)$ \\
\hline Metformin & $78.5 \%(1,245)$ \\
\hline Sulfonylurea & $33.3 \%(528)$ \\
\hline Diet & I.I (I8) \\
\hline Cardiovascular disease ${ }^{\mathrm{b}}$ & $29.3 \%(465)$ \\
\hline
\end{tabular}

Notes: ${ }^{a}$ Continuous variables (with non-Gaussian distribution) are indicated by their median (interquartile range). ${ }^{b}$ Categorical variables are presented by percentage (absolute frequency) in the sample.

Abbreviations: DM, diabetes mellitus; BMI, body mass index; HBP, high blood pressure; HDLc, high-density lipoprotein cholesterol; LDLc, low-density lipoprotein cholesterol; DPP, dipeptidyl peptidase.
$73.4 \% ; P=0.042)$, diabetic polyneuropathy ( $85 \%$ vs $35.2 \%$; $P<0.001)$, and retinopathy (36.7\% vs $19.4 \% ; P<0.001$ ). Patients with pancreatitis had a significantly lower HDLc values ( $35 \mathrm{vs} 44 \mathrm{mg} / \mathrm{dL} ; P<0.001)$ and a higher prevalence of cardiovascular diseases ( $65 \%$ vs $27.9 \% ; P<0.001)$.

No association between diabetes treatment and the presence of pancreatitis was found. The detailed comparison between patients with versus without pancreatitis can be found in Table 2.

\section{Univariate logistic regressions}

In the univariate logistic regression models, the impact of glycemic control on the presence of pancreatitis using the $\mathrm{HbA1c}$ values as well as the average values of fasting glycemia and postprandial glycemia was analyzed. An increase in the risk of developing pancreatitis for all the three variables (odds ratio $[\mathrm{OR}]=1.282 ; 95 \%$ confidence interval $[\mathrm{CI}]$, $1.133-1.451 ; P<0.001),(\mathrm{OR}=1.016 ; 95 \%$ CI, $1.012-1.019$; $P<0.001)$, and (OR $=1.022 ; 95 \% \mathrm{CI}, 1.018-1.026 ; P<0.001)$, respectively, for every 1 percentage point increase in the $\mathrm{HbA1c}$ value as well as the fasting glycemia and postprandial glycemia values was noted. In addition, DM-related complications, such as polyneuropathy and retinopathy, were significant risk factors for pancreatitis ( $[\mathrm{OR}=10.436$; 95\% CI, 5.098-21.363; $P<0.001]$ and $[\mathrm{OR}=2.406 ; 95 \% \mathrm{CI}$, $1.402-4.129 ; P<0.001])$.

HDLc was found to be a significant protective factor against the risk of pancreatitis $(\mathrm{OR}=0.936 ; 95 \% \mathrm{CI}$, $0.913-0.96 ; P<0.001)$. On the contrary, high LDLc values were a significant risk factor for pancreatitis along with high non-HDLc and high TG values ([OR $=1.013$; 95\% CI, 1.009-1.017; $P<0.001]$ and $[\mathrm{OR}=1.004 ; 95 \% \mathrm{CI}$, $1.003-1.005 ; P<0.001]$ ), respectively.

\section{Multivariate logistic regression}

A binomial logistic regression was performed to ascertain the effects of independent variables on the likelihood that patients had pancreatitis. A Bonferroni correction was applied using all eight terms in the model resulting in statistical significance being accepted when $P<0.0025$. Based on this assessment, all continuous independent variables were found to be linearly related to the logit of the dependent variable.

The logistic regression model was statistically significant, $\chi^{2}(12)=276.925, P<0.0005$. The model explained $58.2 \%$ (Nagelkerke $R^{2}$ ) of the variance in the presence of pancreatitis. Of the 11 predictor variables, only seven were statistically significant: gender, $\mathrm{HbA} 1 \mathrm{c}$ value, average fasting glycemia, average postprandial glycemia, TG level, presence 
Table 2 Comparison between groups: patients with pancreatitis versus patients without pancreatitis

\begin{tabular}{|c|c|c|c|}
\hline Studied parameter & With pancreatitis & Without pancreatitis & $P$-value \\
\hline Number of patients & 60 & $\mathrm{I}, 526$ & \\
\hline Age (years) ${ }^{\mathrm{a}}$ & $59(53.25-67)$ & $59(54-66)$ & 0.857 \\
\hline Sex ${ }^{b}$ (male) & $58.3 \%(35)$ & $50.7 \%(774)$ & 0.247 \\
\hline DM type (type 2) & $93.3 \%(56)$ & $92.3 \%(1,409)$ & 0.775 \\
\hline $\mathrm{HbAlc}(\%)^{\mathrm{a}}$ & $8.5(8.1-9.7)$ & $7.7(6.9-8.9)$ & $<0.001$ \\
\hline Fasting glycemia $(\mathrm{mg} / \mathrm{dL})^{\mathrm{a}}$ & $167.5(\mid 52.5-200.25)$ & $95(82-114)$ & $<0.001$ \\
\hline Postprandial glycemia $(\mathrm{mg} / \mathrm{dL})^{\mathrm{a}}$ & $244.5(194.5-288.75)$ & $118(96-157)$ & $<0.001$ \\
\hline BMI $\left(\mathrm{kg} / \mathrm{m}^{2}\right)^{\mathrm{a}}$ & $30.4(27.63-33)$ & $30(26.8-33.2)$ & 0.512 \\
\hline Hypertension ${ }^{\mathrm{b}}$ & $85 \%(5 I)$ & $73.4 \%(1,145)$ & 0.042 \\
\hline Alcohol $^{b}$ & $26.7 \%(16)$ & $27.7 \%(423)$ & 0.858 \\
\hline Smoking ${ }^{\mathrm{b}}$ & $35 \%(21)$ & $32.9 \%(502)$ & 0.734 \\
\hline Gallstones $^{\mathrm{b}}$ & $21.7 \%(13)$ & $19.9 \%(304)$ & 0.740 \\
\hline Total cholesterol $(\mathrm{mg} / \mathrm{dL})^{\mathrm{a}}$ & $256.5(220-297.75)$ & $189.5(156-226)$ & $<0.001$ \\
\hline HDLc (mg/dL) $)^{\mathrm{a}}$ & $35(3 \mid-4 I .75)$ & $44(37-52)$ & $<0.001$ \\
\hline $\operatorname{LDLc}(\mathrm{mg} / \mathrm{dL})^{\mathrm{a}}$ & $208.7 \mid(|59.7|-255)$ & II $2.8(80.8-14 \mid .8)$ & $<0.001$ \\
\hline Non-HDLc (mg/dL) ${ }^{\mathrm{a}}$ & $219(181-265.5)$ & $143(111.75-179)$ & $<0.001$ \\
\hline Triglycerides $(\mathrm{mg} / \mathrm{dL})^{\mathrm{a}}$ & $495(4 \mid 3.25-668.25)$ & $161(109-236)$ & $<0.001$ \\
\hline Diabetic polyneuropathy ${ }^{\mathrm{b}}$ & $85 \%(5 I)$ & $35.2 \%(537)$ & $<0.001$ \\
\hline Diabetic peripheral arteriopathy ${ }^{b}$ & $8.3 \%(5)$ & $9.6 \%(147)$ & 0.737 \\
\hline Diabetic retinopathy ${ }^{\mathrm{b}}$ & $36.7 \%(22)$ & $19.4 \%(296)$ & 0.001 \\
\hline \multicolumn{4}{|l|}{ Treatment $^{\mathrm{b}}$} \\
\hline DPP-4 inhibitors (yes) & $0 \%(0)$ & $0.7 \%(10)$ & 0.534 \\
\hline Insulin (yes) & $31.7 \%(19)$ & $37.2 \%(567)$ & 0.388 \\
\hline Metformin (yes) & $80 \%(48)$ & $78.4 \%(1,197)$ & 0.773 \\
\hline Sulfonylurea (yes) & $30 \%(18)$ & $33.4 \%(510)$ & 0.529 \\
\hline Diet (yes) & $0 \%(0)$ & $1.2 \%(18)$ & 0.398 \\
\hline Cardiovascular disease $^{\mathrm{b}}$ & $65 \%(39)$ & $27.9 \%(426)$ & $<0.001$ \\
\hline Cardiovascular comorbidities ${ }^{\mathrm{a}, \mathrm{C}}$ & $I(0-1)$ & $0(0-1)$ & $<0.001$ \\
\hline
\end{tabular}

Notes: a Continuous variables (with non-Gaussian distribution) are indicated by their median (interquartile range). ${ }^{b}$ Categorical variables are presented by percentage (absolute frequency) in the sample. ${ }^{c}$ Number of associated cardiovascular comorbidities. ${ }^{d} P$-value was computed by using Mann-Whitney $U$ test for continuous variables (with non-Gaussian distribution) and Pearson chi-square test for nominal variables.

Abbreviations: DM, diabetes mellitus; BMI, body mass index; HBP, high blood pressure; HDLc, high-density lipoprotein cholesterol; LDLc, low-density lipoprotein cholesterol; DPP, dipeptidyl peptidase.

of polyneuropathy, and presence of peripheral arteriopathy (Table 3). Males had 8.303 times higher odds of developing pancreatitis than females, OR 95\% CI (3.254-21.187). Increasing $\mathrm{HbA} 1 \mathrm{c}$ as well as fasting and postprandial glycemia were associated with an increased likelihood of developing pancreatitis, OR 95\% CI (1.061-1.626), OR 95\% CI (1.002-1.015), and OR 95\% CI (1.011-1.023), respectively, but increasing HDLc was associated with a decreased likelihood of exhibiting pancreatitis, OR 95\% CI (0.948-1.029) (Figure 2).

\section{Discussion}

While gallstones and alcohol abuse are responsible for $80 \%$ of the AP cases, HTG is the next important trigger, being found in up to $7 \%$ of cases. ${ }^{19,20}$

Alongside the inherited causes of HTG, the most important predisposing factors are high lipid and carbohydrate intake, lack of physical activity, and obesity. ${ }^{12}$ The negative
Table 3 Predictors for pancreatitis in patients with DM (multivariate logistic regression model; Nagelkerke $R^{2}=0.582$ )

\begin{tabular}{|c|c|c|c|c|}
\hline \multirow[t]{2}{*}{ Predictor variables } & \multirow[t]{2}{*}{ OR } & \multicolumn{2}{|l|}{$95 \% \mathrm{Cl}$} & \multirow[t]{2}{*}{$P$-value } \\
\hline & & Lower & Upper & \\
\hline Gender $^{a}$ & 8.303 & 3.254 & 21.187 & $<0.001$ \\
\hline $\mathrm{HbAlc}(\%)^{*}$ & 1.313 & $1.06 \mathrm{I}$ & 1.626 & 0.012 \\
\hline Fasting glycemia $(\mathrm{mg} / \mathrm{dL})^{*}$ & 1.008 & 1.002 & 1.015 & 0.011 \\
\hline Postprandial glycemia $(\mathrm{mg} / \mathrm{dL})^{*}$ & 1.017 & 1.011 & 1.023 & $<0.001$ \\
\hline Total cholesterol (mg/dL) & 0.982 & 0.961 & 1.004 & 0.104 \\
\hline $\mathrm{HDLc}(\mathrm{mg} / \mathrm{dL})$ & 0.988 & 0.948 & 1.029 & 0.555 \\
\hline LDLc (mg/dL) & 1.017 & 0.996 & 1.038 & 0.109 \\
\hline Triglycerides $(\mathrm{mg} / \mathrm{dL})^{*}$ & 1.004 & 1.002 & 1.005 & $<0.001$ \\
\hline Polyneuropathy* & 5.960 & 2.431 & 14.615 & $<0.001$ \\
\hline Peripheral arteriopathy & 0.537 & 0.275 & 1.051 & 0.069 \\
\hline Retinopathy & 0.893 & 0.468 & 1.704 & 0.732 \\
\hline $\mathrm{CV}$ comorbidities $^{\mathrm{b}}$ & 1.426 & 0.844 & 2.411 & 0.185 \\
\hline
\end{tabular}

Notes: a Gender is for males compared to females. ${ }^{b}$ Number of associated CV comorbidities. *Predictor variable is significant both independently and as a co-factor.

Abbreviations: HDLc, high-density lipoprotein cholesterol; LDLc, low-density lipoprotein cholesterol; CV, cardiovascular. 

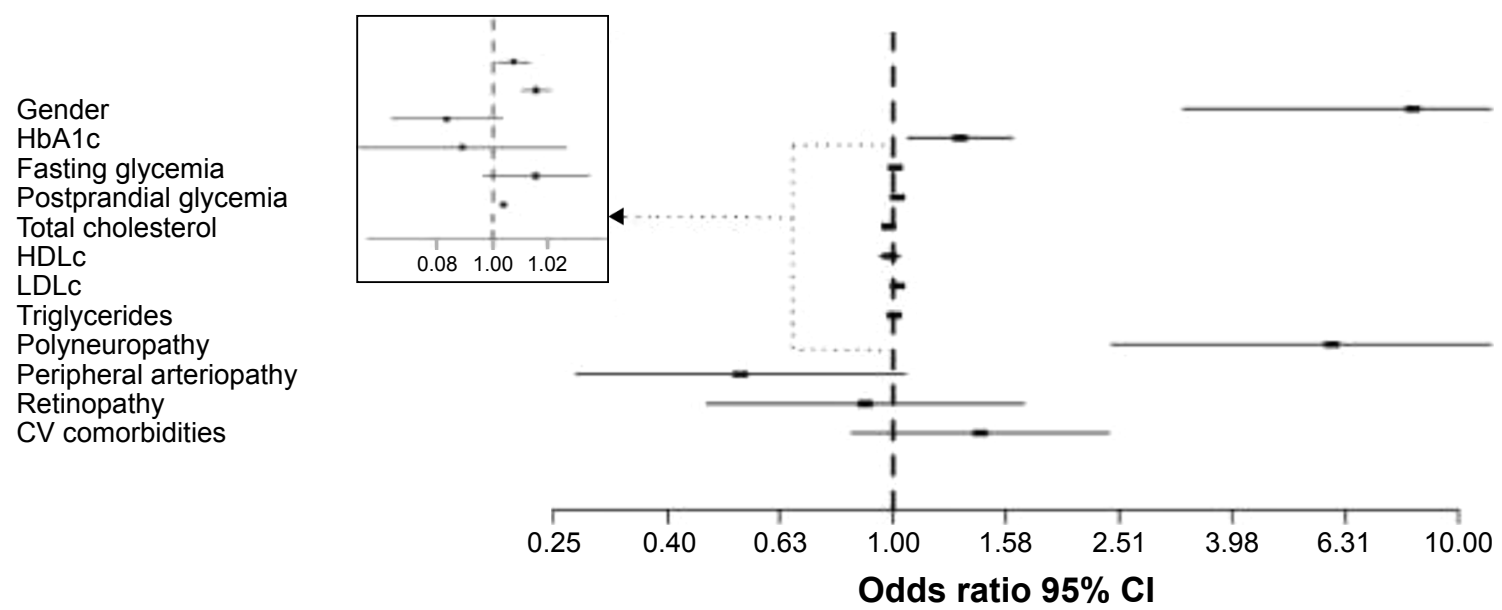

Figure 2 Multivariate risk analysis for pancreatitis in DM patients. The risk is expressed per I percentage point increase for HbAlc, and I mg/dL point increase for fasting glycemia, postprandial glycemia, total cholesterol, HDLc, LDLc, and TGs. For polyneuropathy, peripheral arteriopathy, and retinopathy, the risk is expressed as dichotomous variables, while for CV comorbidities, the risk is expressed per one associated CV comorbidity.

Abbreviations: HDLc, high-density lipoprotein cholesterol; LDLc, low-density lipoprotein cholesterol; CV, cardiovascular.

impact that the metabolic syndrome (MS), dysglycemia, and abdominal obesity have on the level of TG is very well known. ${ }^{21-23}$ Insulin resistance and DM both are associated with high levels of TG due to the insulin-dependent inhibition of lipolysis in the adipocyte and with the increased hepatic production of VLDL and TG. Also, the activation of the insulin-dependent lipoprotein lipase (LPL) and the hydrolyzation of lipoprotein-rich TG are affected. ${ }^{15,23}$

There is a direct correlation between high TG levels and $\mathrm{AP}$, such that mild or moderate increases are considered to be an epiphenomenon, while significant increases of TG $(>1,000 \mathrm{mg} / \mathrm{dL})$ can trigger AP. ${ }^{19,20}$ Similar to cholesterol, TGs are generated from endogenous and exogenous sources. When TGs come from exogenous sources, they are embedded in chylomicrons, while endogenous TGs are synthesized in the liver and embedded in VLDL. Chylomicrons are usually formed $1-3$ hours postprandial and are eliminated within 8 hours. Even so, when TG levels are $>1,000 \mathrm{mg} / \mathrm{dL}$, chylomicrons are permanently present in the circulation. ${ }^{24}$ These low-density particles are very large, being capable of obstructing capillaries, leading to local ischemia. These local lesions can expose TG to pancreatic lipase. The degradation of TG to free fatty acids determine cytotoxic lesions, freeing inflammatory mediators and free radicals, leading to AP. ${ }^{25}$ These two lipoproteins are the most important sources of TG and interact with the LPL in the peripheral tissues, in order to store TG in muscles and adipose tissue. Therefore, the appearance of HTG depends on the balance between the synthesis and catabolism of lipoproteins. Secondary HTG has multiple etiologies, among which the most common are alcohol abuse, DM, poor diet, obesity, estrogens, hypothyroidism, and some drugs (thiazides, betablockers, and protease inhibitors).

The presence of clinical and physical signs that are suggestive for AP has not been very well documented in patients suffering from HTG. ${ }^{6}$ Median TG values of $51.8 \mathrm{mmol}$ and $50.5 \mathrm{mmol}$ have been reported in patients with AP, but a clear TG limit value above which HTG could be established as a definitive cause of AP has not been identified. Previous studies have underlined an increased incidence of DM in patients with HTG-induced AP: $73 \%$ and $43 \%$. AP as a consequence of HTG develops only in the cases in which TG values are $>20 \mathrm{mmol}(1,772 \mathrm{mg} / \mathrm{dL}) .{ }^{26}$

The prevalence of AP was $3.7 \%$ among the patients enrolled in the study. AP patients presented an unsatisfactory glycemic control: the median value of $\mathrm{HbA} 1 \mathrm{c}$ was $8.5 \%$ in those with $\mathrm{AP}$ and $7.7 \%$ in those without $\mathrm{AP}(P<0.001)$. Also, the median values of the fasting and postprandial glycemia were higher in patients who presented AP $(P<0.001)$.

Data collected in this study revealed the fact that increased TG values, especially $>500 \mathrm{mg} / \mathrm{dL}$, are accompanied by an increased risk of AP, while increased HDLc is associated with a significant decrease of said risk $(P<0.001)$.

It seems that patients with AP have a significantly higher cardiovascular risk, proven by the association of AP with arterial hypertension and chronic complications of DM, such as diabetic retinopathy, cardiovascular disease, diabetic peripheral artery disease, or diabetic polyneuropathy. The main modifications that incur in the lipid metabolism in diabetic patients are increased TG values, reduced HDL2 fraction and HDL2/HDL3 ratio, the presence of small and dense LDL (phenotype B) particles that are highly atherogenic, 
increased free fatty acid concentration, increased LP, and prolonged postprandial lipemia. ${ }^{16}$

The formation of small and dense LDL particles is a consequence of the pathogenic mechanism of chronic HTG which amplifies the exchange of lipidic fractions between VLDL and chylomicrons, on one side, and LDL and HDL, on the other. As a result of this exchange, we have LDL particles that are poor in cholesterol and have excess TG.

Chronic hyperglycemia causes the glycosylation of the ApoB100 within the LDL structure, which induces the glycosylation of the LDL particles, making them more electronegative and more sensitive to oxidation with significant atherogenic implications. ${ }^{16,18}$

This study demonstrates that besides other complications or comorbidities, like adverse pregnancy outcomes, ${ }^{27}$ balance impairments, ${ }^{28}$ or decreased quality of life, ${ }^{29}$ already proven in Romanian population to be associated with DM, the AP events are having the previously described set of particularities. The importance of the results of the study is emphasized by the fact that, to the authors' knowledge, this is the first study that analyzes the association between DM and AP incidence in our region. The main limitations of this study are related to its retrospective design, which did not make further collection or dynamic analysis of the cohort possible.

\section{Conclusion}

The prevalence of AP was 3.7\% among the patients enrolled in the study. HTG represents one of the most important risk factors for AP, especially in diabetic patients. The data of this study have proven a strong correlation between AP and unsatisfactory glycemic control (quantified through $\mathrm{HbA} 1 \mathrm{c}$ levels and fasting and postprandial glycemic values), increased TG values, the presence of AHT, as well as the onset and progression of diabetic chronic complications.

Lifestyle optimization by reducing lipid and carbohydrate intake and engaging in physical activities, alongside early and intensive pharmacologic therapeutic strategies, represents the optimal approach in the management of both DM and dyslipidemia (especially HTG), thus preventing the possible occurrence of AP episodes.

\section{Disclosure}

The authors report no conflicts of interest in this work.

\section{References}

1. Fagenholz PJ, Castillo CF, Harris NS, Pelletier AJ, Camargo CA Jr. Increasing United States hospital admissions for acute pancreatitis, 1988-2003. Ann Epidemiol. 2007;17:491-497.
2. Peery AF, Dellon ES, Lund J, et al. Burden of gastrointestinal disease in the United States: a 2012 update. Gastroenterology. 2012;143: $1179-1187$.

3. Stimac D, Mikolasevic I, Krznaric-Zrnic I, Radic M, Milic S. Epidemiology of acute pancreatitis in the North Adriatic region of Croatia during the last ten years. Gastroenterol Res Pract. 2013;2013:956149.

4. Banks PA. Epidemiology, natural history, and predictors of disease in acute and chronic pancreatitis. Gastrointest Endosc. 2002;56: S226-S230.

5. Yang AL, Vadhavkar S, Singh G, Omary MB. Epidemiology of alcoholrelated liver and pancreatic disease in the United States. Arch Intern Med. 2008;168:649-656.

6. Fortson MR, Freedman SN, Webster PD. Clinical assessment of hyperlipidemic pancreatitis. Am J Gastroenterol. 1995;90:2134-2139.

7. Badalov N, Baradarian R, Iswara K, Li J, Steinberg W, Tenner S. Drug-induced acute pancreatitis: an evidence-based review. Clin Gastroenterol Hepatol. 2007;5:648-661.

8. Besselink MG, van Santvoort HC, Boermeester MA, et al. Timing and impact of infections in acute pancreatitis. Br J Surg. 2009;96: 267-273.

9. Wu BU, Johannes RS, Kurtz S, Banks PA. The impact of hospitalacquired infection on outcome in acute pancreatitis. Gastroenterology. 2008;135:816-820.

10. Lowenfels AB, Maisonneuve P, Sullivan T. The changing character of acute pancreatitis: epidemiology, etiology, and prognosis. Curr Gastroenterol Rep. 2009;11:97-103.

11. Papachristou GI, Muddana V, Yadav D, et al. Comparison of BISAP, Ranson's, APACHE-II, and CTSI scores in predicting organ failure, complications, and mortality in acute pancreatitis. Am J Gastroenterol. 2010;105(2):435-441.

12. Serban V, Brink S, Timar B, et al. An increasing incidence of type 1 diabetes mellitus in Romanian children aged 0 to 17 years. $J$ Pediatr Endocrinol Metab. 2015;28(3-4):293-298.

13. Yadav D, Lowenfels AB. Trends in the epidemiology of the first attack of acute pancreatitis: a systematic review. Pancreas. 2006;33:323-330.

14. Expert Panel on Detection, Evaluation, and Treatment of High Blood Cholesterol in Adults. Executive summary of the Third Report of the National Cholesterol Education Program (NCEP) Expert Panel on detection, evaluation, and treatment of high blood cholesterol in adults (Adult Treatment Panel III). JAMA. 2001;285:2486-2497.

15. Verges BL. Dyslipidaemia in diabetes mellitus. Review of the main lipoprotein abnormalities and their consequences on the development of atherogenesis. Diabetes Metab. 1999;25(Suppl 3):32-40.

16. Taskinen MR. Diabetic dyslipidemia: from basic research to clinical practice. Diabetologia. 2003;46:733-749.

17. Brunzell JD, Deeb SS. Familial lipoprotein lipase deficiency, apo CII deficiency and hepatic lipase deficiency. In: Scriver CR, Beaudet AL, Sly WS, Valle D, editors. The Metabolic and Molecular Bases of Inherited Disease. New York: McGraw-Hill; 2001.

18. Tushuizen ME, Diamant M, Heine RJ. Postprandial dysmetabolism and cardiovascular diseases in type 2 diabetes. Postgrad Med J. 2005; $81: 1-6$.

19. Gan SL, Edwards AL, Symonds CJ, Beck PL. Hypertriglyceridemiainduced pancreatitis: a case-based review. World J Gastroenterol. 2006;12(44):7197-7202.

20. Yadav D, Pitchumoni CS. Issues in hyperlipidemic pancreatitis. J Clin Gastroenterol. 2003;36(1):54-62.

21. Alberti KG, Zimmet P, Shaw J; IDF Epidemiology Task Force Consensus Group. The metabolic syndrome - a new worldwide definition. Lancet. 2005;366:1059-1062.

22. McPherson R, Frohlich J, Fodor G, Genest J; Canadian Cardiovascular Society. Canadian Cardiovascular Society position statement recommendations for the diagnosis and treatment of dyslipidemia and prevention of cardiovascular disease. Can J Cardiol. 2006;22: 913-927.

23. Yuan G, Al-Shali KZ, Hegele RA. Hypertriglyceridemia: its etiology, effects and treatment. CMAJ. 2007;176:1113-1120. 
24. Leaf DA. Chylomicronemia and the chylomicronemia syndrome: a practical approach to management. Am J Med. 2008;121(1):10-12.

25. Truninger K, Schmid PA, Hoffmann MM, Bertschinger P, Ammann RW. Recurrent acute and chronic pancreatitis in two brothers with familial chylomicronemia syndrome. Pancreas. 2006;32:215-219.

26. Lloret LC, Pelletier AL, Czernichow S, et al. Acute pancreatitis in a cohort of 129 patients referred for severe hypertriglyceridemia. Pancreas. 2008;(1):13-18.

27. Timar B, Timar R, Albai A, Stoian D, Nitu R, Craina M. Predictors for pregnancy outcomes in Romanian women with type 1 diabetes mellitus: a prospective study. Diabetol Metab Syndr. 2014;6(1):125.
28. Timar B, Timar R, Gaita L, Oancea C, Levai C, Lungeanu D. The impact of diabetic neuropathy on balance and on the risk of falls in patients with type 2 diabetes mellitus: a cross-sectional study. PLoS One. 2016; 11(4): $\mathrm{e} 0154654$.

29. Timar R, Velea I, Timar B, et al. Factors influencing the quality of life perception in patients with type 2 diabetes mellitus. Patient Prefer Adherence. 2016;10:2471-2477.

\section{Publish your work in this journal}

Therapeutics and Clinical Risk Management is an international, peerreviewed journal of clinical therapeutics and risk management, focusing on concise rapid reporting of clinical studies in all therapeutic areas, outcomes, safety, and programs for the effective, safe, and sustained use of medicines. This journal is indexed on PubMed Central, CAS,
EMBase, Scopus and the Elsevier Bibliographic databases. The manuscript management system is completely online and includes a very quick and fair peer-review system, which is all easy to use. Visit http://www.dovepress.com/testimonials.php to read real quotes from published authors.

Submit your manuscript here: http://www.dovepress.com/therapeutics-and-clinical-risk-management-journal 